\title{
Investigation of Fixed Oil of Gallus gallus domesticus for Various Pharmacological Activities
}

Nadeem A, Ali H, Anwaar M and J abeen Q* Department of Pharmacology, Faculty of Pharmacy, The Islamia University of Bahawalpur, Pakistan

*Correspondling author: Qaiser J abeen, Chairperson, Department of Pharmacology, Faculty of Pharmacy, The Islamia University of Bahawalpur, Pakistan

Received: May 29, 2021; Accepted: J une 18, 2021; Published: J une 25, 2021

\begin{abstract}
Medicinal oils, including fixed and essential oils, are one of the most ancient forms of medicines. Animals and plants are the major source of fixed oils which have been reported to treat various ailments, such as urinary, nervous, respiratory, cardiovascular, musculoskeletal disorders, bacterial, fungal and protozoal infections etc. Medicinal oils, especially of animal origin are; however, ignored and rarely investigated in contemporary modern medical research. This study was aimed to investigate the various pharmacological activities of fixed oil of Gallus gallus domesticus (Egg oil, Fo.Gg).
\end{abstract}

Fo.Gg was investigated for its wound healing potential by using excisional wound model, anti-arthritic activity by following turpentine oil-induced acute arthritis model, antipyretic activity by yeast-induced pyrexia, anxiolytic activity by adopting hole board, light/dark exploration and elevated plus maze models, antidepressant activity by forced swim test and tail suspension model and antiamnesic activity by Y-maze model.

Fo.Gg showed significant healing potential as evident from increase in percent wound contraction and decrease in period of epithelialization and also the significant decrease in paw and ankle joint diameter in anti-arthritic activity. It showed dose-dependent (i.e. 10, 30 and 50\%) decrease in rectal temperature when compared to the control group, also showed significant anxiolytic, antidepressant and anti-amnesic activities. These pharmacological activities may be attributed to the antioxidant as well as radical scavenging potential of oil components especially polyphenols, oleic acid and linoleic acid.

Thus, the results of the study conclude that egg oil possesses wound healing, anti-arthritic, antipyretic, anxiolytic, antidepressant and anti-amnesic potential. The study provides scientific ground for the folkloric use of the oil in traditional system of medicine; however, further studies are required to explore the possible mechanism(s) of action.

Keywords: Egg oil; Antiarthritic; Antipyretic; Anxiolytic; Antidepressant; Anti-amnesic

\section{Abbreviations}

DNP: Donepezil; DZP: Diazepam; DHA: Docosahexaenoic Acid; EPM: Elevated Plus Maze; EPA: Eicosapentaenoic Acid; Fo.Gg: Fixed oil of Gallus gallus domesticus; FST: Forced Swim Test; FXT: Fluoxetine; GLA: Gamma Linoleic Acid; HBM: Hole Board Model; LDE: Light/Dark Exploration Test; PCM; Paracetamol; PGE2: Prostaglandin E2; PEA: Palmitoyl Ethanolamide; PUFAs: Polyunsaturated fatty acids; TSM: Tail Suspension Model; UFAs: Unsaturated fatty acids

\section{Introduction}

Oils are amongst the earliest forms of natural medicines. Oils, herbs, animals and mineral medicines have been used since ancient times to treat various illnesses, such as urinary, nervous, respiratory, gastrointestinal, reproductive, cardiovascular, musculoskeletal disorders, cancer, diabetes, bacterial, fungal and protozoal infections etc. Medicinal oils have been used to target particular areas of the body to combat particular ailments via oral, topical or nasal routes of administration [1]. Animals and plants are the major sources of fixed oils. In animals, fixed oils can be found in the fats of subcutaneous and retroperitoneal tissues. The chemical structure of fixed oils consists of one glycerol attached to three fatty acids known as triglycerides. These triglycerides can be unsaturated, monosaturated or polysaturated, depending upon the number of hydrogen atoms attached to hydrocarbon tails of fatty acids and the number of double bonds [2]. Medicinal oils, especially of animal origin, are rarely investigated in contemporary modern medicine. Therefore, this study was designed to evaluate the pharmacological activities of fixed oil of Gallus gallus domesticus (Fo.Gg, Egg oil). Egg oil is a multipurpose medicine, with specific uses in pyrexia and dermatological indications. Triglycerides, cholesterol, phospholipids and free fatty acids are the major components of egg oil. It is widely used in Japan, Korea, Asia and China. Chinese medical encyclopaedia, Flora Sinensis, describes it as a remedy for every disease, with specific indication in head ulcers, skin sores and mild fever with diarrhoea in children. Egg oil has been reported to possess anti-inflammatory, analgesic and healing potential in burn $[3,4]$. 
The study was designed to investigate the pharmacological activities of Fo.Gg for wound healing (by excisional wound model), acute arthritis (by turpentine oil-induced arthritis), anti-pyretic (using yeast-induced pyrexia), anxiolytic (by hole board, elevated plus maze and light/dark exploration models), anti-amnesic (scopolamineinduced dementia in Y-maze test) and antidepressant (forced swim test and tail suspension model) activities to provide scientific ground to the folkloric claims of fixed oil of Gallus gallus domesticus.

\section{Methodology}

\section{Material and equipment}

All the material used in this research were locally purchased or procured from the store of faculty of Pharmacy, the Islamia University of Bahawalpur, including Vaseline (Oval Pharmaceuticals, Lahore, Pakistan), Tween-80 (Sigma Aldrich, USA), Diazepam (MartinDow, Switzerland), Scopolamine (Sigma Aldrich, USA), Donepezil (ATCO Laboratories Limited, Karachi, Pakistan), Fluoxetine (Hilton, Pakistan), Aspirin (Reckitt Benckiser Pakistan LTD), Turpentine oil, Ketamine (Global Pharmaceuticals, Islamabad, Pakistan), Xylazine (My Lab, Bahawalpur, Pakistan) and Fixed oil of Gallus gallus domesticus (Fo.Gg) was locally purchased from Shadab Dawakhana, Bahawalpur, Pakistan.

\section{Preparation of formulation}

Three formulations, for topical application of Fo.Gg, were prepared at different concentrations; i.e. 10, 30 and 50\% w/w, using vaseline as vehicle. Three suspensions, for oral administration, were also prepared (10, 30 and $50 \% \mathrm{v} / \mathrm{v}$ of Fo.Gg) using $1 \%$ tween- 80 as vehicle.

\section{Experimental animals}

Healthy adult Wistar albino rats of either sex weighing from 200$280 \mathrm{~g}$ and Swiss albino mice of either sex weighing from 20-40g were housed in Pharmacology research lab, department of Pharmacology, faculty of Pharmacy, the Islamia University of Bahawalpur, under standard environmental conditions; i.e. 12h light/dark cycle and $23 \pm 2^{\circ} \mathrm{C}$. Animals were fed with standard diet and water ad libitum. All the experimental guidelines of this research were approved by the Pharmacy Animal Ethics Committee (PAEC) under reference number PAEC/2020/28.

\section{Wound healing activity}

The effects of Fo.Gg on wound healing were investigated by following the excisional wound model of Nayak and Pereira (2006) with slight modifications [5]. Wistar albino rats were divided into different groups each comprising of six animals. Prior to the wound induction, animals were anesthetized and hair was removed from cervical region. Two equal sized circular wounds $(6 \mathrm{~mm})$ were made by using one-hole perforateur, toothed forceps and scissors. After wound induction each animal was kept in an individual cage.

The control (i.e. untreated) group was observed until the wounds were completely healed. Thin layer of vaseline was topically applied on the wounds of vehicle control group. Fo.Gg was applied topically, as a thin layer, in different concentrations (i.e. 10, 30 and 50\%) and size of wounds measured for 14 days (i.e. $3^{\text {rd }}, 7^{\text {th }}, 10^{\text {th }}$ and $14^{\text {th }}$ ), mean of both the wounds were taken and percent wound contraction was calculated.
$\%$ Wound contraction $=($ Initial wound size - Specific day wound size) $\times 100$

\section{Initial wound size}

Period of complete epithelialization was also calculated as the number of days required to completely heal the wounds and falling off the dead skin, individually for all the groups.

\section{Antiarthritic activity}

To evaluate the anti-arthritic potential of Fo.Gg, turpentine oilinduced acute arthritis model was followed by Alamgeer et al., (2015) and Uttra and Hasan, (2017) with slight modifications [6,7]. Wistar albino rats were randomly divided into different groups, each group comprising of 6 animals. Normal paw and ankle joint size of each animal was measured by using vernier caliper at $0 \mathrm{hr}$. Diseased control group received $1 \%$ Tween- 80 ( $5 \mathrm{ml} / \mathrm{kg}$; p.o), standard group received Aspirin (100mg/kg; p.o) and the treatment groups received 10, 30 and $50 \%$ of Fo.Gg ( $5 \mathrm{ml} / \mathrm{kg}$; p.o), individually. After $1 \mathrm{hr}$ of administration of respective treatments, $0.05 \mathrm{ml}$ of turpentine oil was injected into the paw. After 1, 2, 3, 4, 5 and 6 hrs of injection, paw and ankle joint size was noted and compared with the diseased control group. Percent inhibition of paw and ankle joint size was also calculated.

\section{Percent inhibition of edema $=(\mathrm{Vc}-\mathrm{Vt}) / \mathrm{Vc} \times 100$}

Where, $\mathrm{Vc}$ is the ankle joint or paw size $(\mathrm{mm})$ of control rats and $\mathrm{Vt}$ is the ankle joint or paw size $(\mathrm{mm})$ of treated.

\section{Antipyretic activity}

To investigate the anti-pyretic effect model used by Javed et al., (2020) was followed for this study with slight modifications [8]. Rats were divided into different groups, each group comprising of six animals. Basal rectal temperature was recorded at $0 \mathrm{hr}$. Pyrexia was induced by injecting $10 \mathrm{ml} / \mathrm{kg}$ of $15 \%$ Brewer's yeast, subcutaneously, then kept the animals on fasting for $18 \mathrm{hr}$. After $18 \mathrm{hrs}$, rectal temperature was recorded again and the animals with the increased rectal temperature of $98-101^{\circ} \mathrm{F}$ were selected. Control group received $1 \%$ Tween-80 (5ml/kg; p.o.), standard group received PCM $(50 \mathrm{mg} /$ kg; p.o.) while treatment groups received 10, 30 and 50\% of Fo.Gg $(5 \mathrm{ml} / \mathrm{kg} ;$ p.o. $)$, respectively and at $1^{\text {st }}, 2^{\text {nd }}, 3^{\text {rd }}, 4^{\text {th }}$ and $5^{\text {th }} \mathrm{hr}$ rectal temperature was recorded.

\section{Anxiolytic activity}

Anxiolytic activity of Fo.Gg was investigated by performing Hole Board Test, Light/Dark Exploration test and Elevated Plus Maze Test. Male Swiss albino mice (20-40g), were randomly divided into different groups each comprising of six animals. Control group received normal saline (10ml $/ \mathrm{kg}$; p.o.), standard group received Diazepam (DZP, $1 \mathrm{mg} / \mathrm{kg}$; p.o.). The treatment group was treated with Fo.Gg (10ml/kg; p.o.). After $1 \mathrm{~h}$ of administration, each animal was individually placed on each of the behavioural apparatus for 5 min and the readings were noted. These experiments were performed in a noise free room with dim illumination. After each observation, apparatus was thoroughly cleaned with alcohol to remove the odour of previous animal.

\section{Hole Board Model (HBM)}

To evaluate anxiolytic activity, HBM was followed Bakre et al., (2013) and Murtala and Akindele, (2020) with slight modifications $[9,10]$. Hole board is a wooden apparatus with the dimensions of 
$40 \times 40 \times 25 \mathrm{~cm}^{3}$, having 16 holes of $25 \mathrm{~cm}$ in diameter, through which mice could peep. Number and duration of head poking was recorded.

\section{Light/Dark Exploration Test (LDE)}

Protocol of this experiment was followed by Murtala and Akindele, 2020 with slight modifications [10]. LDE apparatus was made up of wood, having two adjacent rooms divided by a wall and had a small hole through which mice could easily move. Each room was of $25 \times 25 \times 25 \mathrm{~cm}^{3}$. One room was painted black and covered, called as dark room, the other room was painted white and uncovered, called as light room. Light room had a 40-watt lamp on it at the height of $25 \mathrm{~cm}$. Time spent in dark and light room was recorded in seconds.

\section{Elevated plus maze test}

The model used by Mora et al [11] was followed with slight modifications. EPM consisted of four arms, two closed and two open with the measurements $35 \times 5 \times 20 \mathrm{~cm}$ of closed arms, $35 \times 5 \mathrm{~cm}$ of open arms. Apparatus was $50 \mathrm{~cm}$ high from the ground level and made up of wood. Time(s) spent in open and closed arms was recorded.

\section{Anti-depressant activity}

To evaluate the antidepressant activity of Fo.Gg, FST and TSM were performed. Mice were divided into different groups each consisting of six animals. Normal control group received normal saline (10ml $/ \mathrm{kg}$; p.o.), standard group received Fluoxetine (FXT, $10 \mathrm{mg} / \mathrm{kg}$; p.o.) and treatment group was treated with Fo.Gg (10ml/ kg; p.o.), respectively.

\section{Forced swim test}

FST is a validated test to investigate the sadness/depression in animals. The model used by Biney et al., 2016 was adopted with slight modifications [12]. FST apparatus is a glass apparatus with the dimensions of $20 \times 12 \mathrm{~cm}$. FST consisted of two swimming sessions in an apparatus filled with water $\left(25 \pm 1^{\circ} \mathrm{C}\right)$ upto $15 \mathrm{~cm}$. First swimming session (pre-test session) was the day before the final test session, it was of $15 \mathrm{~min}$ without the administration of any drug or medicinal substance. After the pre-test session, animals were treated thrice with their respective group treatments (i.e. 24, 6 and $1 \mathrm{~h}$ ) before the final test session. After $1 \mathrm{hr}$ of last dose, animals were placed individually in the FST apparatus for $5 \mathrm{~min}$ and immobility time was recorded in seconds.

\section{Tail suspension model}

To evaluate the anti-depressant activity by TSM, Murtala and Akindele, 2020 model was followed with slight modifications [10]. TSM apparatus is a rectangular wooden box, $70 \mathrm{~cm}$ in length and an iron rod is attached in between the side walls which is $60 \mathrm{~cm}$ high from the ground and $10 \mathrm{~cm}$ low from the top. TSM was of two sessions; pretest session and final test session. Animals were hung individually to the iron rod with the help of an adhesive tape, in pre-test session for $15 \mathrm{~min}$, one day before the final test session. The animals were treated with their respective group treatment after the pre-test session (i.e. 24, 6 and $1 \mathrm{~h}$ ) before the final test session. After $1 \mathrm{hr}$ of administration of final dose, animals were hung individually with the iron rod, mobility and immobility time was recorded for $5 \mathrm{~min}$.

\section{Anti-amnesic activity}

To investigate the effects of Fo.Gg on scopolamine-induced dementia in Y-maze test, procedure adopted by Kim et al., 2013 was folloed with slight modifications [13]. Wistar albino rats were divided into different groups each comprising of 6 animals. All the animals were intoxicated with Scopolamine (1.5mg/kg, i.p.), except the normal control group. After 30min of intoxication, animals received their respective group treatment. Normal control and intoxicated group received $1 \%$ Tween 80 (5ml/kg; p.o), standard group, Donepezil (DNP, $5 \mathrm{mg} / \mathrm{kg}$; p.o) and the treatment groups received 10, 30 and 50\% of Fo.Gg (5ml/kg; p.o), individually. Y-maze is a wooden apparatus consisted of three equal sized arms $(43 \times 15 \times 12 \mathrm{~cm})$, symmetrically disposed at $120^{\circ}$. Arms were marked as A, B and C.

After $1 \mathrm{hr}$ of administration of respective group treatments, animals were placed individually in centre of $\mathrm{Y}$-maze and observed the sequence (i.e; $\mathrm{ABCCBABCB}$ ), total arm entries and total number of alternations were noted for $5 \mathrm{~min}$. An alternation was recorded when animal chose to enter into all the 3 arms on consecutive choices (e.g. $\mathrm{ABC}, \mathrm{BCA}, \mathrm{BAC}$, but not $\mathrm{BAB}$ ), apparatus was thoroughly cleaned after each observation to remove the odour of previous animal. Percent alternation was calculated.

Percent alternation $(\%)=$ Total number of alternations $\times 100$

Total number of arm entries

\section{Acute toxicity of Fo.Gg}

Acute toxicity was performed to evaluate the toxic potential of Fo.Gg by following the OECD guidelines. Swiss albino mice of either sex (20-40g) were selected and divided into different groups, each group comprising of 5 animals. Animals were acclimatized to the laboratory conditions before the performance, they were kept in standard environmental conditions and fed with rodent dietary pallets and water ad libitum. The animals were kept on fasting $6 \mathrm{hrs}$ before the toxicity study. Different doses of Fo.Gg were given orally; i.e. 1, $3,5,7.5$ and $10 \mathrm{ml} / \mathrm{kg}$. Normal control group received $1 \%$ Tween- 80 ( $10 \mathrm{ml} / \mathrm{kg} ;$ p.o). All the animals were observed critically for $2 \mathrm{hr}$ and then at the interval of $30 \mathrm{~min}$ for next $6 \mathrm{~h}$ for any type of behavioural changes and then mortality rate was noted for the next $48 \mathrm{~h}[8,14]$.

\section{Statistical analysis}

The results were presented as mean \pm SEM. The data was evaluated by using statistical software Graph Pad Prism version 08 . The statistical analysis was done by using one and two-way Analysis of Variance (ANOVA) following Bonferroni's post hoc test and considered non-significant if $\mathrm{p}>0.05$ and significant when $\mathrm{p}<0.05$.

\section{Results and Discussion}

\section{Acute toxicity of Fo.Gg}

According to the OECD guidelines, acute toxicity of Fo.Gg was performed and no signs of toxicity and mortality were observed and found to be safe upto $10 \mathrm{ml} / \mathrm{kg}$.

\section{Wound healing activity}

Percent wound contraction of control (i.e. untreated group) group was $35.4 \pm 1.4$, however vehicle control group showed $62.5 \pm 1.8$ and treatment groups (i.e.10, 30 and 50\%) exhibited $97.2 \pm 0.8,100 \pm 0.0$ and $100 \pm 0.0$, respectively, at $14^{\text {th }}$ day. Period of epithelialization (days) of untreated group was $19.1 \pm 0.5,18.1 \pm 0.3$ of vehicle control group and $14.7 \pm 0.6,12.2 \pm 0.3$ and $9.5 \pm 0.3$ of 10,30 and $50 \%$ of Fo.Gg, respectively. Fo.Gg showed significant and dose-dependent healing 
a

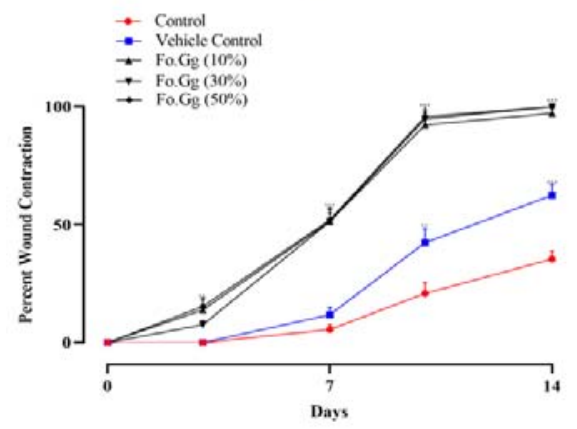

b

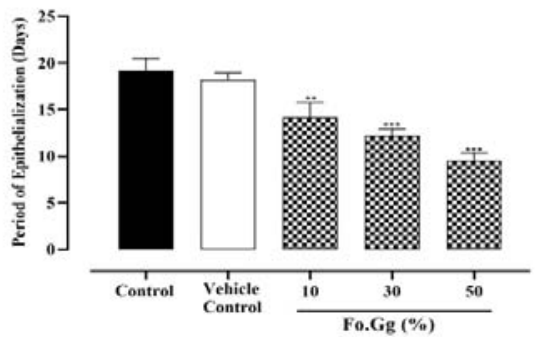

Figure 1: The effects of Fo.Gg on (1a) percent wound contraction and (1b) period of epithelialization in excisional wound model. $\mathrm{n}=6$; Mean \pm SEM $p<0.05:^{*} ; p<0.01::^{* *}$ and $p<0.001::^{* * *}$

a

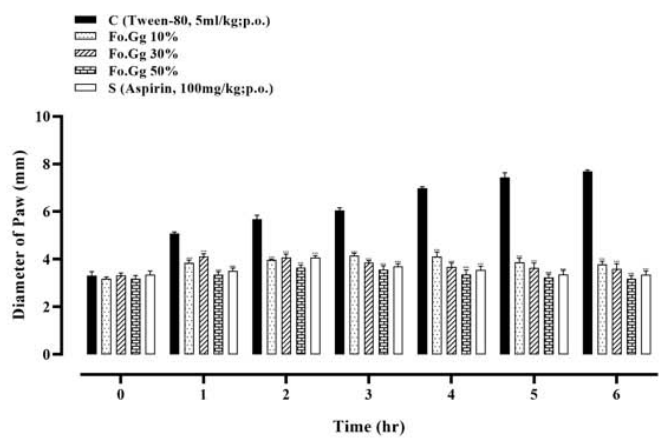

b

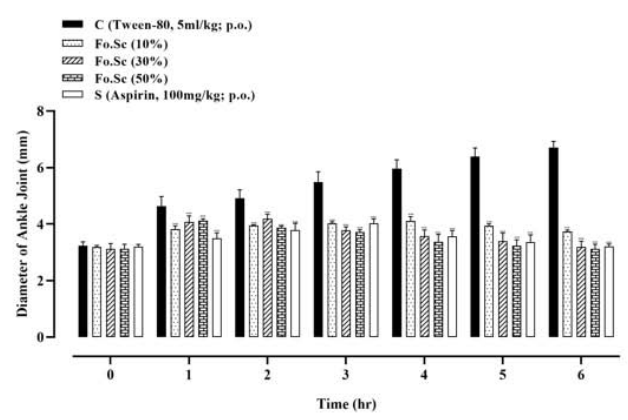

Figure 2: The effects of Fo.Gg on (2a) paw size and (2b) ankle joint size ( $\mathrm{mm}$ ) in turpentine oil-induced arthritis. $\mathrm{n}=6$; Mean \pm SEM

$p<0.05:^{* ;} ; p<0.01:^{* *}$ and $p<0.001:^{* * *}$

potential (Figure 1a and 1b).

Healing of a wound is the process of repairing or restoring the physical integrity of external or internal structures of the body [15]. It involves inflammatory reactions, proliferation and tissue remodelling. According to the previous studies, animal and plant extracted oils and fatty acids possess wound healing potential $[16,17]$ and deficiency of Essential Fatty Acids (EFAs) such as linoleic or oleic acid, results in delayed wound healing. Both oleic and linoleic acid can alter the function and composition of membrane rafts through eicosanoidindependent mechanism [18]. PUFAs such as omega-3 and omega-6, have been reported to change the cellular functions, protective effect toward normal tissues, non-toxic to normal cells and modify phospholipids of cell membranes and help in tissue regeneration and healing the wounds, both have been reported to be present in egg oil $[3,19]$. Eicosanoids that are derived from omega-6 PUFAs; i.e. arachidonic acid, have pro-inflammatory and immunoactive functions; however, eicosanoids derived from omega-3 such as Eicosapentaenoic Acid (EPA) and Docosahexaenoic Acid (DHA), have anti-inflammatory and wound healing potential and inhibit the production of arachidonic acid (17). As egg oil is rich in oleic acid, linoleic acid and DHA [19], the egg oil has wound healing potential as evident from increase in percent wound contraction and decrease in period of epithelialization.

\section{Anti-arthritic activity}

Paw and ankle joint size of control group was moderately increased to a maximum size of $7.7 \pm 0.0$ and $6.7 \pm 0.1 \mathrm{~mm}$, respectively, at $6 \mathrm{~h}$. The paw and ankle joint size of the standard and treatment groups (i.e. 10, 30 and 50\%, Fo.Gg) significantly decreased when compared to the control group (Figure $2 \mathrm{a}$ and $2 \mathrm{~b}$ ). Percent inhibition of paw and ankle joint edema of treatment groups increased dose dependently when compared to the control group (Table 1). Traditional medicine practitioners in northern Iran assume that the egg oil has analgesic activity. Considering the anti-inflammatory and analgesic capability of egg oil [4]. This study was designed to explore its antiarthritic potential. To assess the antiarthritic potential, turpentine oilinduced arthritis model was followed. Turpentine oil induces acute inflammation, characterized by marked vasodilation and enhance vascular permeability. It also causes the release of inflammatory mediators in three different phases, histamine and serotonin release in early phase, kinin in mid phase and prostaglandins in later phase $[6,20]$.

Fixed oils of Linum usitatissimum and Ocimum sanctum have been reported to possess antiarthritic potential because of the presence of linoleic acid, PUFAs downregulate inflammatory reactions which inhibit the release of Prostaglandin $\mathrm{E}_{2}\left(\mathrm{PGE}_{2}\right)$ and decrease 
Table 1: The effects Fo.Gg on percent inhibition of paw and ankle joint edema in turpentine oil-induced arthritis.

\begin{tabular}{|c|c|c|c|c|c|c|c|c|c|c|c|c|c|}
\hline \multirow{2}{*}{\multicolumn{2}{|c|}{ Groups }} & \multicolumn{6}{|c|}{ Percent Inhibition of Paw Edema (\%) } & \multicolumn{6}{|c|}{ Percent Inhibition of Ankle Joint Edema (\%) } \\
\hline & & 1h & $2 \mathrm{~h}$ & 3h & $4 \mathrm{~h}$ & $5 \mathrm{~h}$ & $6 h$ & $1 \mathrm{~h}$ & $2 \mathrm{~h}$ & $3 h$ & $4 \mathrm{~h}$ & $5 \mathrm{~h}$ & $6 h$ \\
\hline \multicolumn{2}{|c|}{$\begin{array}{c}\text { Standard } \\
\text { (Aspirin, 100mg/ } \\
\text { kg; p.o.) }\end{array}$} & $31.0 \pm 1.1^{*+* t}$ & $28.2 \pm 1.2^{* * *}$ & $38.7 \pm 1.2^{* * *}$ & $49.1 \pm 1.0^{* * *}$ & $54.8 \pm 1.2^{* * * *}$ & $56.2 \pm 1.0^{* * *}$ & $24.5 \pm 1.2^{4 * * x}$ & $22.8 \pm 1.3^{* * * *}$ & $26.2 \pm 1.3^{\text {tit+ }}$ & $40.1 \pm 1.4^{* * *}$ & $47.5 \pm 0.8^{* *+x}$ & $52.1 \pm 0.9^{*+*}$ \\
\hline \multirow{3}{*}{$\begin{array}{c}\text { Fo.Gg } \\
(5 \mathrm{ml} / \mathrm{kg} \\
\text { p.o.) }\end{array}$} & $10 \%$ & $23.4 \pm 1.1^{*+1+}$ & $30.1 \pm 0.8^{*+*}$ & $31.2 \pm 0.7^{\star * *}$ & $41.1 \pm 1.1^{* * *}$ & $47.8 \pm 1.1^{* * *}$ & $50.5 \pm 1.0^{* * *}$ & $16.9 \pm 3.2^{+* *+}$ & $19.2 \pm 2.2^{n+1+}$ & $26.2 \pm 2.0^{*+*}$ & $30.8 \pm 2.4^{*+*+4}$ & $38.3 \pm 1.5^{*+*+1}$ & $44.3 \pm 0.8^{+*+1}$ \\
\hline & $30 \%$ & $18.1 \pm 0.8^{* * * t}$ & $28.6 \pm 0.7^{4 * *}$ & $36.3 \pm 0.4^{*+* t+}$ & $47.3 \pm 0.9^{* * *+}$ & $51.2 \pm 1.3^{* * *+}$ & $52.9 \pm 1.2^{* * *+}$ & $11.5 \pm 4.4^{* * *}$ & $14.2 \pm 3.0^{4 *+*}$ & $30.9 \pm 1.3^{* *+*}$ & $40.1 \pm 1.1^{* * *+}$ & $486.9 \pm 1.9^{*+*}$ & $52.4 \pm 0.8^{*+*}$ \\
\hline & $50 \%$ & $34.2 \pm 1.1^{* * *}$ & $35.6 \pm 0.9^{* * *}$ & $40.9 \pm 1.4^{* * *}$ & $51.8 \pm 1.1^{* * *}$ & $56.5 \pm 0.9^{* * * *}$ & $58.4 \pm 0.9^{* * *}$ & $10.7 \pm 2.4^{*+* x}$ & $20.8 \pm 1.7^{\star \star * t}$ & $32.1 \pm 1.5^{\text {t*t* }}$ & $43.4 \pm 1.2^{* * *}$ & $49.4 \pm 1.1^{* * *}$ & $53.5 \pm 0.6^{* * *}$ \\
\hline
\end{tabular}

$\mathrm{n}=6$; Mean \pm SEM

$p<0.05:^{*} ; p<0.01:^{* *}$ and $p<0.001:^{* * *}$

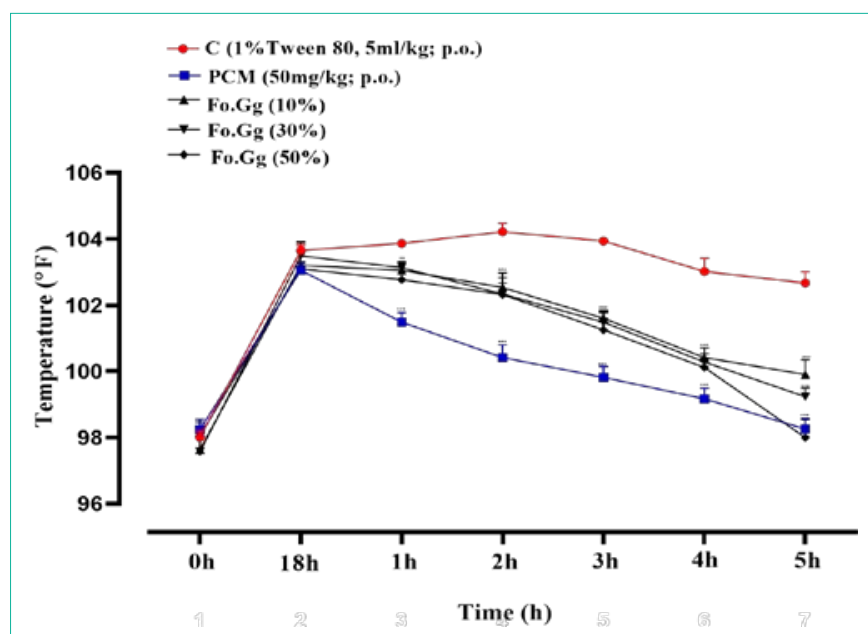

Figure 3: The effects of Fo.Gg on rectal temperature $\left({ }^{\circ} \mathrm{F}\right)$ in yeast-induced pyrexia.

$\mathrm{n}=6$; Mean \pm SEM

$p<0.05:^{* *} p<0.01:^{* *}$ and $p<0.001:^{* * *}$

the vascular permeability. Moreover, polyphenols and antioxidant potential have been reported to be efficient in chronic inflammatory disorders [21-23]. Gamma Linoleic Acid (GLA) and Palmitoyl Ethanolamide (PEA) are present in egg oil. GLA has been reported to have anti-inflammatory action, and modulates the prostaglandins, leukotrienes and cytokines. PEA and its analogue adelmidrol, have been reported to have antiinflammatory and anti-anaphylactic activity by down regulation of proinflammatory mediators (e.g. nitric oxide and TNF-alpha) release in early phase of inflammation and mast cell degranulation [14,24].

\section{Antipyretic activity}

Standard group (PCM, 50mg/kg; p.o.) was significantly reduced the temperature at $1^{\text {st }}$ hour when compared to the control group and showed persistent effects for $6 \mathrm{hrs}$. Temperature of standard and treatment groups reduced to normal, dose dependently (Figure 3). Treatment groups showed the significant results when compared to the control group.

Yeast induces pathogenic pyrexia by acting as exogenous pyrogenic agent and stimulates the endogenous pyrogens; i.e. interleukin-1 and tumor necrosis factor from monocytes and leukocytes, act on thermo-receptive region of hypothalamus to release arachidonic acid, which stimulates the production of prostaglandins which cause increase in hypothalamic set point. Non-steroidal anti-inflammatory drugs decrease the levels of prostaglandins by inhibiting the synthesis

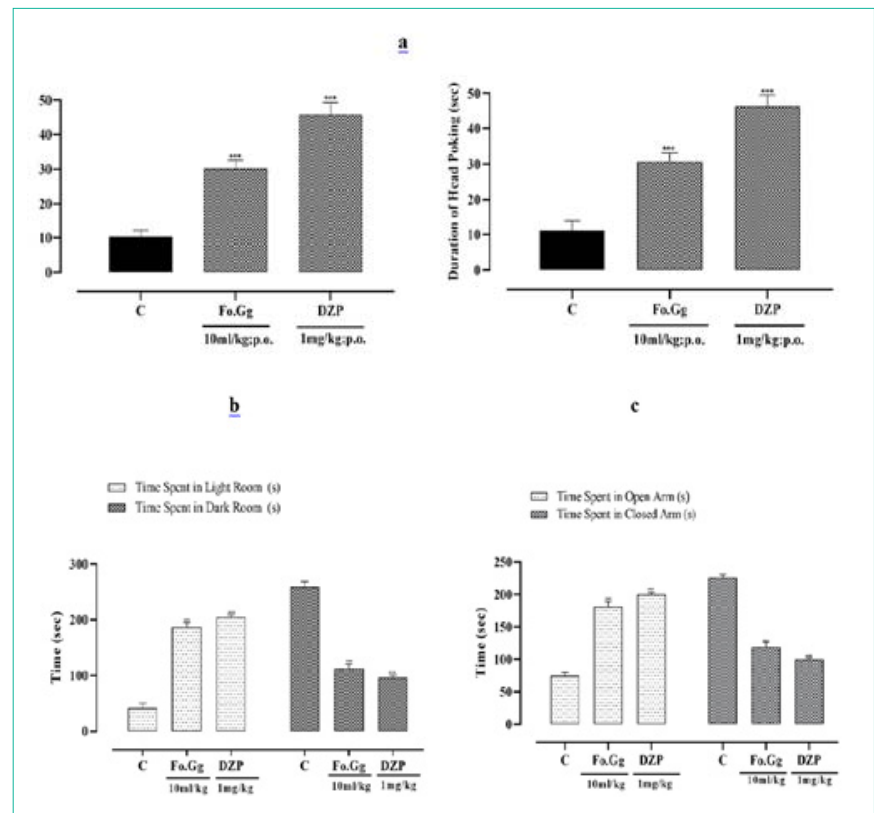

Figure 4: The effects of Fo.Gg and DZP (Diazepam), the standard anxiolytic drug, on (4a) duration and number of head poking in HBM, (4b) time spent in light and dark room in LDE and (4c) time spent in open and closed arms (s) in EPM.

$\mathrm{n}=6$; Mean \pm SEM

$p<0.05:^{*} ; p<0.01:^{* *}$ and $p<0.001:^{* * *}$

in hypothalamus via cyclooxygenase pathway, which causes the reduction in temperature [25]. Essential oil of Lippia multiflora [26], Calamintha sylvatica [27], virgin coconut oil, clove oil, Caesalipinia bonducella seed oil, fixed oil of Ocimum sanctum and Linum usitatissimum L. have been reported to possess antipyretic activities and have inhibitory actions on the production of prostaglandin E2 $[8,23,28,29]$. Considering the antipyretic activity of these fixed oils, antipyretic activity of Fo.Gg was investigated. Egg oil is mentioned in Chinese medical encyclopaedia Flora Sinensis, as a remedy of fever and diarrhoea in children [3]. Mostly, antipyretic agents centrally inhibit the production of PGE2 [8], from the results it can be suggested that egg oil inhibits the production of PGE2 resulting in antipyretic effects.

\section{Anxiolytic activity}

Standard and treatment groups showed more number and duration of head poking when compared to the control group in HBM. In LDE, standard and treatment groups spent more time in light room as compared to the control group. In EPM, standard and treatment groups spent more time in open arm and showed 


$$
\text { Immobility Time (s) }
$$

Mobility Time (s)

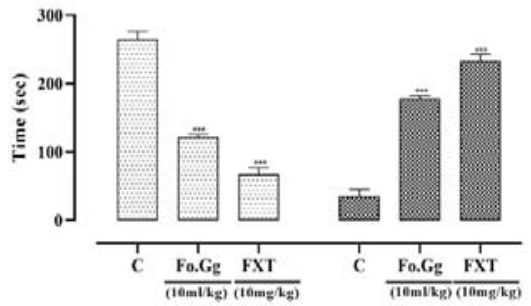

b

$\square$ Inmobility Time (s)

m Mobility Time (s)

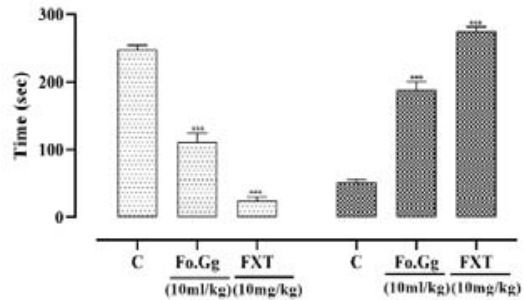

Figure 5: The effects of Fo.Gg and FXT (Flouxetine), the standard antidepressant drug, on (5a) mobility and immobility time(s) in FST and (5b) mobility and immobility time(s) in TSM.

$\mathrm{n}=6$; Mean \pm SEM

$p<0.05:^{*} ; p<0.01:^{* *}$ and $p<0.001:^{* * *}$

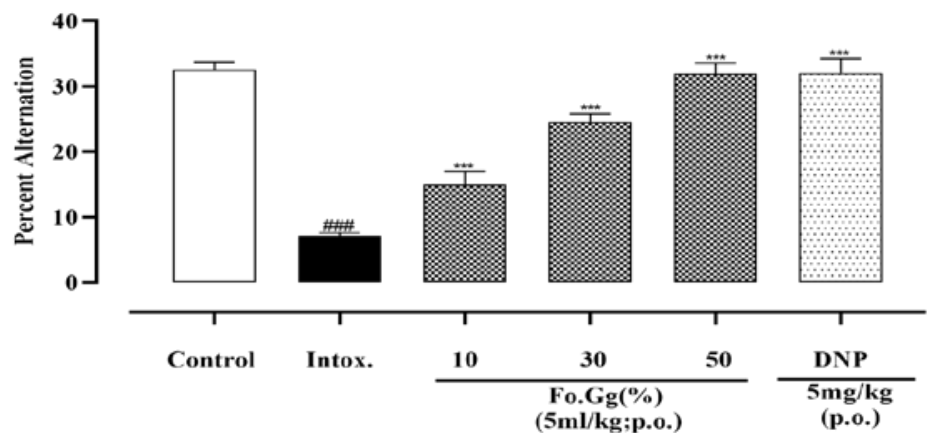

Figure 6: The effects of Fo.Gg and DNP (Donepezil), the standard drug, on percent alternation in scopolamine-induced dementia

$\mathrm{n}=6$; Mean \pm SEM

$p<0.05:^{*} ; p<0.01^{* *}$ and $p<0.001:^{* * *}$

significant difference when compared to the control group (Figure $4 \mathrm{a}, 4 \mathrm{~b}$ and $4 \mathrm{c}$ ). Fatty acid mixture of oleic, linoleic, stearic, palmitic, palmitoleic and myristic acid have been reported to possess anxiolytic activity [30,31]. Egg oil has been reported to have $65 \%$ of linoleic, palmitic and oleic acid [19].

\section{Anti-depressant activity}

In FST and TSM, standard and treatment groups were more mobile and showed significant difference when compared to the control group (Figure 5a and 5b). FST and TSM are most widely used animal models to assess the antidepressant activity [32]. Thus, time is the best parameter to evaluate depressive state of the animal [33]. Increase in mobility time indicates antidepressant activity [34]. Omega-3 has therapeutic potential in neurological and psychiatric diseases. Alpha linoleic acid, carotenoids, phenolic contents and antioxidant potential are responsible for antidepressant activity $[35,36]$.

\section{Anti-amnesic activity}

Control group showed $32.5 \pm 0.5 \%$ alternation. The intoxicated group significantly reduced the percentage alternations; i.e. 7.1 \pm 0.2 , when compared to the control group. Percentage alternations of Fo.Gg increased in dose dependent manner (i.e. 10, 30 and 50\%) when compared to the intoxicated group and exhibited significant $(\mathrm{p}<0.001)$ results (Figure 6).

Scopolamine belongs to the class of non-selective cholinergic antagonist cause partial memory deficit or amnesia. It causes decrease in cholinergic function in hippocampus and in cerebral cortex; i.e. involves in learning and memory process. Thus, it is widely used to cause dementia in animal models by damaging the learning and memory functions. Therefore, donepezil represents as AChE inhibitor and increase cholinergic activity and that's why it was justified to use it as a standard drug against scopolamine induced dementia. Y-maze is a hippocampus-dependent spatial memory task. It is used to evaluate short term memory. Anxiety and depression are also common in patients with memory impairment [37]. Oxidative stress can cause brain damage, learning impairment and memory deficit. Egg oil has been reported to possess antioxidant potential [13,38,39], which supports the results of this study. Fo.Gg might inhibits AChE activity and by enhancing the cholinergic functions.

Multiple components have been reported to be present in egg oil; such as oleic acid, linoleic acid, palmitic acid, stearic acid, linolenic acid, EPA, DHA carotenoids, terpenoids, PEA all of which possess strong antioxidant potential $[3,4,19]$. Fo.Gg showed highly significant wound healing potential after application of 10, 30 and $50 \%$ oil preparations as evident from increase in percent wound contraction and decrease in period of epithelialization, significant 
decrease in diameter of paw and ankle joint at respective intervals and results were found comparable with those of the standard drug, aspirin $(100 \mathrm{mg} / \mathrm{kg})$, when tested by turpentine oil-induced acute arthritis model. Fo.Gg showed dose-dependent reduction in rectal temperature when compared to the control group, also showed significant anxiolytic activity, antidepressant activity and antiamnesic activity. These pharmacological activities of Fo.Gg may be attributed to the antioxidant as well as radical scavenging potential of oil components especially polyphenols, oleic acid and linoleic acid.

\section{Conclusions of the Study}

The results of the study conclude that the fixed oil of Gallus gallus domesticus (Fo.Gg) possesses various pharmacological activities including wound healing, anti-arthritic, antipyretic, anxiolytic, antidepressant and anti-amnesic activities. Therefore, this study provides scientific ground to the folkloric use of fixed oil of Gallus gallus domesticus (Egg oil, Fo.Gg) in traditional system of medicine; however, further studies are required to encourage the possible mechanism(s) of action.

\section{References}

1. Hamedi A, Zarshenas MM, Sohrabpour M, Zargaran A. Herbal medicinal oils in traditional Persian medicine. Pharmaceutical Biology. 2013; 51: 12081218.

2. Kumar GS, Jayaveera KN. A textbook of pharmacognosy and phytochemistry. 1 ed: S. Chand Publishing. 2014.

3. Hu TM, Lan TH, Loh EW. An emerging complimentary medicine-yolk oil made from heating method. Journal of Traditional and Complementary Medicine. 2012; 2: 202-203.

4. Mahmoudi M, Ebrahimzadeh MA, Pourmorad F, Rezaie N, Mahmoud MA. Anti-inflammatory and analgesic effects of egg yolk: a comparison between organic and machine made. European Review for Medicine and Pharmacology Science. 2013; 17: 472-476.

5. Nayak B, Pereira LMP. Catharanthus roseus flower extract has woundhealing activity in Sprague Dawley rats. BMC Complementary and Alternative Medicine. 2006; 6: 1-6.

6. Alamgeer, Hasan UH, Uttra AM, Rasool S. Evaluation of in vitro and in vivo anti-arthritic potential of Berberis calliobotrys. Bangladesh Journal of Pharmacology. 2015; 10: 807-819.

7. Uttra AM, Hasan UH. Anti-arthritic activity of aqueous-methanolic extract and various fractions of Berberis orthobotrys Bien ex Aitch. BMC Complementary and Alternative Medicine. 2017; 17: 1-16.

8. Javed F, Jabeen Q, Aslam N, Awan AM. Pharmacological evaluation of analgesic, anti-inflammatory and antipyretic activities of ethanolic extract of Indigofera argentea Burm. f. Journal of Ethnopharmacology. 2020; 259: 112966.

9. Bakre AG, Aderibigbe AO, Ademowo OG. Studies on neuropharmacological profile of ethanol extract of Moringa oleifera leaves in mice. Journal of Ethnopharmacology. 2013; 149: 783-789.

10. Murtala AA, Akindele AJ. Anxiolytic-and antidepressant-like activities of hydroethanol leaf extract of Newbouldia laevis (P. Beauv.) Seem. (Bignoniaceae) in mice. Journal of Ethnopharmacology. 2020; 249: 112420.

11. Mora S, Veliz GD, Lungenstrass H, González MG, Morales TC, Poletti C, et al. Central nervous system activity of the hydroalcoholic extract of Casimiroa edulis in rats and mice. Journal of Ethnopharmacology. 2005; 97: 191-197.

12. Biney RP, Benneh CK, Ameyaw EO, Gyasi EB, Woode E. Xylopia aethiopica fruit extract exhibits antidepressant-like effect via interaction with serotonergic neurotransmission in mice. Journal of Ethnopharmacology. 2016; 184: 49-57.

13. Kim EJ, Jung IH, Le TKV, Jeong JJ, Kim NJ, Kim DH. Ginsenosides Rg5 and $\mathrm{Rh} 3$ protect scopolamine-induced memory deficits in mice. Journal of
Ethnopharmacology. 2013; 146: 294-299.

14. Gilani AH, Jabeen Q, Khan AU, Shah AJ. Gut modulatory, blood pressure lowering, diuretic and sedative activities of cardamom. Journal of Ethnopharmacology. 2008; 115: 463-472.

15. Nagar HK, Srivastava AK, Srivastava R, Kurmi ML, Chandel HS, Ranawat MS. Pharmacological investigation of the wound healing activity of Cestrum nocturnum (L.) ointment in Wistar albino rats. Journal of Pharmaceutics. 2016; 2016: 1-8.

16. Nevin KG, Rajamohan T. Effect of topical application of virgin coconut oil on skin components and antioxidant status during dermal wound healing in young rats. Skin Pharmacology and Physiology. 2010; 23: 290-297.

17. Wall R, Ross RP, Fitzgerald GF, Stanton C. Fatty acids from fish: the antiinflammatory potential of long-chain omega-3 fatty acids. Nutrition Reviews. 2010; 68: 280-289.

18. Farahpour MR, Vahid M, Oryan A. Effectiveness of topical application of ostrich oil on the healing of Staphylococcus aureus-and Pseudomonas aeruginosa-infected wounds. Connective Tissue Research. 2018; 59: 212 222.

19. Walczak J, Bocian S, Kowalkowski T, Trziszka T, Buszewski B. Determination of omega fatty acid profiles in egg yolk by HILIC-LC-MS and GC-MS. Food Analytical Methods. 2017; 10: 1264-1272.

20. Kumar V, Verma A, Ahmed D, Sachan NK, Anwar F, Mujeeb M. Fostered antiarthritic upshot of Moringa oleifera Lam. stem bark extract in diversely induced arthritis in wistar rats with plausible mechanism. International Journal of Pharmceutical Sciences and Research. 2013; 4: 3894-3901.

21. Farcaș AD, Moț AC, Pârvu AE, Toma VA, Popa MA, Mihai MC, et al. In Vivo Pharmacological and Anti-inflammatory Evaluation of Xerophyte Plantago sempervirens Crantz. Oxidative Medicine and Cellular Longevity. 2019; 2019.

22. Kaithwas G, Majumdar DK. Therapeutic effect of Linum usitatissimum (flaxseed/linseed) fixed oil on acute and chronic arthritic models in albino rats. Inflammopharmacology. 2010; 18: 127-136.

23. Singh S, Majumdar D. Effect of fixed oil of Ocimum sanctum against experimentally induced arthritis and joint edema in laboratory animals. International Journal of Pharmacognosy. 1996; 34: 218-222.

24. Filippis DD, D'Amico A, Cinelli MP, Esposito G, Di Marzo V, luvone T. Adelmidrol, a palmitoylethanolamide analogue, reduces chronic inflammation in a carrageenin-granuloma model in rats. Journal of Cellular and Molecular Medicine. 2009; 13: 1086-1095.

25. Intahphuak S, Khonsung P, Panthong A. Anti-inflammatory, analgesic, and antipyretic activities of virgin coconut oil. Pharmaceutical Biology. 2010; 48: 151-157.

26. Abena AA, Diatewa M, Gakosso G, Gbeassor M, Hondi-Assah TH, Ouamba JM. Analgesic, antipyretic and anti-inflammatory effects of essential oil of Lippia multiflora. Fitoterapia. 2003; 74: 231-236.

27. Urbina AVDO, Martin ML, Montero MJ, Moran A, Roman LS. Sedating and antipyretic activity of the essential oil of Calamintha sylvatica subsp. ascendens. Journal of Ethnopharmacology. 1989; 25: 165-171.

28. Shukla S, Mehta A, Mehta P, Vyas SP, Shukla S, Bajpai VK. Studies on antiinflammatory, antipyretic and analgesic properties of Caesalpinia bonducella F. seed oil in experimental animal models. Food and Chemical Toxicology. 2010; 48: 61-64.

29. Taher YA, Samud AM, El-Taher FE, Hussin GB, Elmezogi JS, Mehdawi $\mathrm{BFA}$, et al. Experimental evaluation of anti-inflammatory, antinociceptive and antipyretic activities of clove oil in mice. Libyan Journal of Medicine. 2015; 10.

30. Contreras CM, Landa JFR, Ríos RIG, Escobedo JC, Ruiz GG, Morales BB. Myristic acid produces anxiolytic-like effects in Wistar rats in the elevated plus maze. BioMed Research International. 2014; 2014.

31. Landa JFR, Ríos RIG, Escobedo JC, Morales BB, Contreras CM. Participation of chloride channels in the anxiolytic-like effects of a fatty acid mixture. BioMed Research International. 2013; 2013.

32. Pollak DD, Rey CE, Monje FJ. Rodent models in depression research: 
classical strategies and new directions. Annals of Medicine. 2010; 42: 252 264.

33. Riaz A, Khan RA. Effect of Punica Granatum on behavior in rats. African Journal of Pharmacy and Pharmacology. 2014; 8: 1118-1126.

34. Taiwo AE, Leite FB, Lucena GM, Barros M, Silveira D, Silva MV, et al Anxiolytic and antidepressant-like effects of Melissa officinalis (lemon balm) extract in rats: Influence of administration and gender. Indian Journal of Pharmacology. 2012; 44: 189.

35. Blondeau N, Nguemeni C, Debruyne DN, Piens M, Wu X, Pan H, et al Subchronic alpha-linolenic acid treatment enhances brain plasticity and exerts an antidepressant effect: a versatile potential therapy for stroke. Neuropsychopharmacology. 2009; 34: 2548-2559.

36. Kumar BA, Lakshman K, Velmurugan C, Sridhar SM, Gopisetty S. Antidepressant activity of methanolic extract of Amaranthus spinosus. Basic and Clinical Neuroscience. 2014; 5: 11.
37. Ohba T, Yoshino $Y$, Ishisaka M, Abe N, Tsuruma K, Shimazawa M, et al. Japanese Huperzia serrata extract and the constituent, huperzine $\mathrm{A}$, ameliorate the scopolamine-induced cognitive impairment in mice. Bioscience, Biotechnology, and Biochemistry. 2015; 79: 1838-1844.

38. Omri B, Alloui N, Durazzo A, Lucarini M, Aiello A, Romano R, et al. Egg yolk antioxidants profiles: effect of diet supplementation with linseeds and tomatored pepper mixture before and after storage. Foods. 2019; 8: 320.

39. Zaki HF, Fattah MAAE, Attia AS. Naringenin protects against scopolamineinduced dementia in rats. Bulletin of Faculty of Pharmacy, Cairo University. 2014; 52: 15-25. 